\title{
Assessment of source water contamination by estrogenic disrupting compounds in China
}

\author{
Weiwei Jiang ${ }^{1}$, Ye Yan ${ }^{1}$, Mei Ma ${ }^{1, *}$, Donghong Wang ${ }^{1}$, Qian Luo ${ }^{1}$, \\ Zijian Wang ${ }^{1}$, Senthil Kumaran Satyanarayanan ${ }^{2}$ \\ 1. Research Center for Eco-Environmental Sciences, Chinese Academy of Sciences, Beijing 100085, China. \\ E-mail: jiang_weiwei@hotmail.com \\ 2. Unit of Toxicology, Bharathiar University, Coimbatore 641046, India
}

Received 24 March 2011; revised 11 May 2011; accepted 13 May 2011

\begin{abstract}
Detection of estrogenic disrupting compounds (EDCs) in drinking waters around China has led to rising concerns about health risks associated with these compounds. There is, however, a paucity of studies on the occurrence and identification of the main compounds responsible for this pollution in the source waters. To fill this void, we screened estrogenic activities of 23 source water samples from six main river systems in China, using a recombinant two-hybrid yeast assay. All sample extracts induced significant estrogenic activity, with E2 equivalents (EEQ) of raw water ranging from 0.08 to $2.40 \mathrm{ng} / \mathrm{L}$. Additionally, 16 samples were selected for chemical analysis by gas chromatography-mass spectrometry. The EDCs of most concern, including estrone (E1), 17 $\beta$-estradiol (E2), $17 \alpha$-ethinylestradiol (EE2), estriol (E3), diethylstilbestrol (DES), estradiol valerate (EV), 4-t-octylphenol (4-t-OP), 4-nonylphenols (4-NP) and bisphenol A (BPA), were determined at concentrations of up to 2.98, 1.07, 2.67, 4.37, 2.52, 1.96, 89.52, 280.19 and 710.65 ng/L, respectively. Causality analysis, involving comparison of EEQ values from yeast assay and chemical analysis identified E2, EE2 and 4-NP as the main responsible compounds, accounting for the whole estrogenic activities (39.74\% to $96.68 \%$ ). The proposed approach using both chemical analysis and yeast assay could be used for the identification and evaluation of EDCs in source waters of China.
\end{abstract}

Key words: source water; estrogenic disrupting compounds; yeast assay; bioassay

DOI: $10.1016 /$ S1001-0742(11)60746-8

\section{Introduction}

Due to the adverse biological effects of estrogenic disrupting compounds (EDCs) in animals, there are increasing concerns that low-level exposure to these compounds might cause similar effects in humans (Damstra et al., 2002). Changes in sex and reproductive ability in aquatic animals are an indication that many environmental pollutants could act as EDCs (Sumpter, 1997). Pharmaceuticals, waste water plant effluents, agricultural fertilizers and fish farming wastes are important man-made sources of these environmental pollutants (Yamazaki, 1983; Desbrow et al., 1998; Tashiro et al., 2003). Moreover, they are not completely removed by many conventional water treatment processes, such as chlorination, coagulation, and sedimentation (Kuch and Ballschmiter, 2001; Magi et al., 2010). Estrogenic activity has been detected in effluents of drinking water treatment plants (DWTP) in China, resulting in increased risks to human health (Rao et al., 2004; Wang et al., 2005; Luo et al., 2006). An additional problem is the absence of water quality threshold standards with regard to estrogenic activity in drinking water in

\footnotetext{
* Corresponding author. E-mail: mamei@rcees.ac.cn
}

China (MOH, 2006). It is therefore necessary to monitor EDCs levels in source water so as to evaluate the risks to humans, protect the ecosystem, and to provide useful information for drinking water treatment.

To screen estrogenic activity in the environment, a number of biological tools have been developed. In vitro bioassays that requires low equipments and has high sensitivities levels have been developed as rapid tools for screening the toxicity of chemical or environmental samples (Campbell et al., 2006). Knowledge of the composition profiles of sample is not required for in vitro bioassays, which are useful for rapid and reliable identification of estrogenic activity of environmental samples or for sampling in the event of pollution emergencies. Among these bioassays, the yeast assay has been successfully applied for determining estrogenic activity of chemicals or environmental samples (Vermeirssen et al., 2005). The composition profiles of the samples and the compounds responsible for the estrogenic activity are not, however, determined via bioassays. This information is necessary to the removal of pollutants or for environmental remediation (Augulyte and Bergqvist, 2007). Combined in vitro bioassays and chemical analysis tools 
have, therefore, now been recognized as effective methods for screening estrogenic chemicals and for environmental risk assessments (Reineke et al., 2002; Matthiessen et al., 2006). Chemical analytical methods, using gas (or liquid) chromatography-mass spectrometry (GS-MS or LC-MS) combined with solid phase extraction (SPE) for determining concentrations of EDCs in water, have proved to be very useful complementary methods associated with bioassays (Kasprzyk-Hordern et al., 2008; Jonkers et al., 2010).

Several works pertaining to the investigation of estrogenic disrupting compounds in surface waters of China make use of bioassays and chemical analysis. Nine compounds of natural and anthropogenic origin are considered in the present study: estrone (E1), 17 $\beta$-estradiol (E2), $17 \alpha$-ethinylestradiol (EE2), estriol (E3), diethylstilbestrol (DES), estradiol valerate (EV), 4-t-octylphenol (4-t-OP), 4-nonylphenols (4-NP) and bisphenol A (BPA). These represent the most frequently discovered EDCs in water bodies in China (Zhao et al., 2009; Lu et al., 2010). It should be noted, however, that few studies on estrogenic activity in source waters, and the compounds involved in such activity, have been undertaken in China. The E2 equivalent (EEQ) approach, which has been proved to be effective in the identification of EDCs in water, was introduced in the present study (Ra et al., 2011). By assessing causal links between activities observed by means of bioassay and chemical levels by chemical analysis, the relevant estrogenic compounds can be identified. The aim of the present work was therefore to screen estrogenic activity levels in 23 source waters in China, and to attempt to identify specific compounds responsible for such activity, to provide useful information for source water protection and drinking water treatment.

\section{Materials and methods}

\subsection{Chemicals and materials}

Target compounds E1, E2, EE2, E3, DES, EV, 4-t-OP, 4-NP, and surrogate compounds E2-d3, BPA-d16 and solvent dimethyl sulfoxide (DMSO), all of which had purity levels higher than $98 \%$, were purchased from Sigma-Aldrich (USA). The derivatization reagent N,Obis(trimethylsilyl)trifluoroacetamide (BSTFA) with $1 \%$ trimethylchlorosilane (TMCS) was purchased from Supelco (USA). All reagents of HPLC grade used (methanol, $n$-hexane, dichloromethane, methyl tertiary butyl ether) were obtained from J. T. Baker (USA). Water used in all experiments was prepared by means of a Milli-Q water purification system (Millipore, USA). Stock solutions of chemicals $(2 \mathrm{mg} / \mathrm{L})$ were prepared in $n$-hexane and stored at $-20^{\circ} \mathrm{C}$. Oasis hydrophilic lipophilic balance (HLB) cartridges (N-vinylpyrrolidone-m-divinylbenzene copolymer, $500 \mathrm{mg}, 6 \mathrm{~mL}$ ), obtained from Waters Corporation (USA) were used for solid phase extraction (SPE). Glass fiber filters (APFF, pore size $0.45 \mu \mathrm{m}$ ) were purchased from Millipore (USA) and pyrolyzed at $450^{\circ} \mathrm{C}$ for $4 \mathrm{hr}$ prior to use.

\subsection{Sample collection}

Samples from 23 source waters, including reservoirs and rivers that supply water to local waterworks, were collected between March 2010 and July 2010 (Table 1). The study area covered six out of the seven main river systems of China.

Samples (20 L for bioassay and $4 \mathrm{~L}$ for chemical analysis) were collected in pre-cleaned amber glass bottles. Prior to sample collection, the bottles were washed three times with water samples. To minimize contamination of samples, throughout sample collection and processing, use of personal care items and pharmaceuticals were discouraged. Immediately after sampling, an appropriate amount of methanol ( $2 \mathrm{~mL} / \mathrm{L}$ in water sample) was added to the $20 \mathrm{~L}$ samples to be used for bioassay, to suppress possible biotic activities. Samples were stored at $4{ }^{\circ} \mathrm{C}$ prior to treatment and were treated and prepared within $48 \mathrm{hr}$.

\subsection{Sample preparation}

Water samples were filtered through pre-baked glass fiber filters to remove insoluble materials and extracted using the SPE method. Two litter source water sample (part 1) for chemical analysis for six estrogens (E1, E2, EE2, E3, DES and EV) was spiked with E2-d3, another $2 \mathrm{~L}$ (part 2) for chemical analysis for 4-t-OP, 4-NP and BPA was spiked with BPA-d16. Samples were extracted using HLB solid phase extraction cartridges, that had been preconditioned with $5 \mathrm{~mL}$ dichloromethane $(5 \mathrm{~mL}$ methyl tert-butyl ether for part 1), $5 \mathrm{~mL}$ methanol and $5 \mathrm{~mL}$ water. During extraction, the cartridges were forced under

Table 1 Site information

\begin{tabular}{|c|c|c|}
\hline Site & Type & Coordinate \\
\hline \multicolumn{3}{|c|}{ Songhua River ${ }^{\mathrm{a}}$} \\
\hline $\mathrm{S} 1$ & River & $126.501^{\circ} \mathrm{E}, 45.764^{\circ} \mathrm{N}$ \\
\hline $\mathrm{S} 2$ & Reservoir & $127.697^{\circ} \mathrm{E}, 44.399^{\circ} \mathrm{N}$ \\
\hline \multicolumn{3}{|c|}{ Liao River } \\
\hline$S 3^{b}$ & Reservoir & $124.101^{\circ} \mathrm{E}, 41.886^{\circ} \mathrm{N}$ \\
\hline $\mathrm{S} 4^{\mathrm{b}}$ & Reservoir & $125.404^{\circ} \mathrm{E}, 41.292^{\circ} \mathrm{N}$ \\
\hline \multicolumn{3}{|c|}{ Hai River } \\
\hline S5 & Reservoir & $116.840^{\circ} \mathrm{E}, 40.490^{\circ} \mathrm{N}$ \\
\hline \multicolumn{3}{|c|}{ Yangtze River } \\
\hline$S 6^{b}$ & River & $106.449^{\circ} \mathrm{E}, 29.597^{\circ} \mathrm{N}$ \\
\hline $\mathrm{S} 7^{\mathrm{b}}$ & River & $106.554^{\circ} \mathrm{E}, 29.570^{\circ} \mathrm{N}$ \\
\hline $\mathrm{S} 8^{\mathrm{b}}$ & River & $106.529^{\circ} \mathrm{E}, 29.508^{\circ} \mathrm{N}$ \\
\hline$S 9^{b}$ & River & $118.694^{\circ} \mathrm{E}, 31.994^{\circ} \mathrm{N}$ \\
\hline $\mathrm{S} 10^{\mathrm{b}}$ & River & $118.798^{\circ} \mathrm{E}, 32.142^{\circ} \mathrm{N}$ \\
\hline $\mathrm{S} 11^{\mathrm{b}}$ & River & $118.717^{\circ} \mathrm{E}, 32.049^{\circ} \mathrm{N}$ \\
\hline $\mathrm{S} 12^{\mathrm{b}}$ & Lake & $120.223^{\circ} \mathrm{E}, 31.517^{\circ} \mathrm{N}$ \\
\hline $\mathrm{S} 13^{\mathrm{b}}$ & Reservoir & $121.357^{\circ} \mathrm{E}, 31.492^{\circ} \mathrm{N}$ \\
\hline $\mathrm{S} 14^{\mathrm{b}}$ & River & $121.308^{\circ} \mathrm{E}, 30.974^{\circ} \mathrm{N}$ \\
\hline $\mathrm{S} 15^{\mathrm{b}}$ & Reservoir & $121.710^{\circ} \mathrm{E}, 31.420^{\circ} \mathrm{N}$ \\
\hline \multicolumn{3}{|c|}{ Huai River } \\
\hline $\mathrm{S} 16^{\mathrm{b}}$ & River & $117.173^{\circ} \mathrm{E}, 34.401^{\circ} \mathrm{N}$ \\
\hline $\mathrm{S} 17^{\mathrm{b}}$ & River & $118.950^{\circ} \mathrm{E}, 33.586^{\circ} \mathrm{N}$ \\
\hline $\mathrm{S} 18^{\mathrm{b}}$ & River & $119.000^{\circ} \mathrm{E}, 33.625^{\circ} \mathrm{N}$ \\
\hline $\mathrm{S} 19^{\mathrm{b}}$ & River & $118.972^{\circ} \mathrm{E}, 33.509^{\circ} \mathrm{N}$ \\
\hline \multicolumn{3}{|c|}{ Pearl River } \\
\hline $\mathrm{S} 20^{\mathrm{b}}$ & Reservoir & $114.603^{\circ} \mathrm{E}, 23.794^{\circ} \mathrm{N}$ \\
\hline $\mathrm{S} 21^{\mathrm{b}}$ & Reservoir & $113.259^{\circ} \mathrm{E}, 23.807^{\circ} \mathrm{N}$ \\
\hline $\mathrm{S} 22^{\mathrm{b}}$ & Reservoir & $114.149^{\circ} \mathrm{E}, 22.571^{\circ} \mathrm{N}$ \\
\hline $\mathrm{S} 23^{\mathrm{b}}$ & River & $110.419^{\circ} \mathrm{E}, 19.885^{\circ} \mathrm{N}$ \\
\hline
\end{tabular}

${ }^{a}$ River system; ${ }^{b}$ selected for chemical analysis. 
vacuum at a flow rate of approximately $6 \mathrm{~mL} / \mathrm{min}$, and then kept under vacuum aspiration for 5 min to dry the residual water. In the end, the cartridges for chemicals analysis were eluted three times with $10 \mathrm{~mL}$ methyl tert-butyl ether for part 1 and $10 \mathrm{~mL}$ dichloromethane for part 2, respectively. Cartridge for bioassay was eluted three times with $5 \mathrm{~mL}$ dichloromethane. The elution was filtered by anhydrous sodiumsulfate to remove water and evaporated to $2 \mathrm{~mL}$ in a rotary evaporator (R-200, Buchi, Switzerland) at $40^{\circ} \mathrm{C}$. Then $2 \mathrm{~mL}$ extract was blown down to dryness under a nitrogen stream and was reconstituted to $0.5 \mathrm{~mL}$ with $n$-hexane (for chemical analysis) and $0.2 \mathrm{~mL}$ with DMSO (for bioassay) immediately. Procedural blank using purified water was also run alongside the samples as an assay control.

\subsection{Yeast assay}

The yeast assay was carried out as described previously by our research group with some modifications (Li et al., 2010). Shortly, the assay encompassed an exponential growth at $30^{\circ} \mathrm{C}, 130 \mathrm{r} / \mathrm{min}$ overnight yeast strain as diluted with synthetic dextrose/-Leu/-Trp medium (SD medium) to an optical density of 0.75 at $600 \mathrm{~nm}\left(\mathrm{OD}_{600}\right)$. All samples were assayed with a minimum in triplicate. Each assay group included a positive control (E2) and a negative control (DMSO). Procedural blank samples, were also run alongside the samples to monitor any false positive results. The effects of estrogenic compounds and water samples were standardized against E2. Each sample was serially diluted in DMSO in a 1:2 series for a total of four concentrations. Five microlitter of serial dilutions of samples tested were combined with $995 \mu \mathrm{L}$ of medium, which contained approximately $5 \times 10^{3}$ yeast cells $/ \mathrm{mL}$, resulting in a test culture in which the volume of DMSO did not exceed $0.5 \%$ of the total volume. The test culture sample of $200 \mu \mathrm{L}$ were transferred into each well of the 96-well plate and incubated at $30^{\circ} \mathrm{C}$ with vigorous orbital shaking $(800 \mathrm{r} / \mathrm{min})$ on a titer plate shaker for $2 \mathrm{hr}$, after which the $\mathrm{OD}_{600}$ was measured. The volume of extract in each well represented $100 \mathrm{~mL}$ raw water. A volume of 150 $\mu \mathrm{L}$ was then removed from test cultures, and $120 \mu \mathrm{L}$ in test buffer and $20 \mu \mathrm{L}$ chloroform were added to the remaining $50 \mu \mathrm{L}$ of the cultures. The cultures were mixed carefully (vortex $25 \mathrm{sec}$ ) and pre-incubated for $10 \mathrm{~min}$ at $30^{\circ} \mathrm{C}$, $1300 \mathrm{r} / \mathrm{min}$. The enzyme reaction was triggered by adding $40 \mu \mathrm{L}$ o-nitrophenyl- $\beta$-D-galactopyranoside, $4 \mathrm{mg} / \mathrm{mL}$ in test buffer, and incubated at $30^{\circ} \mathrm{C}, 800 \mathrm{r} / \mathrm{min}$ on a titer plate shaker. One hundred microlitter sodium carbonate of $106 \mathrm{~g} / \mathrm{L}$ was then added to terminate the reactions within $60 \mathrm{~min}$, after which $200 \mu \mathrm{L}$ of the supernatant was transferred to a new 96-well plate and the optical density measured at $420 \mathrm{~nm}\left(\mathrm{OD}_{420}\right)$. To ensure that the activities taking place in the bioassay were caused by true antagonistic responses and not cytotoxicity, the cell viability was also measured. After exposure, cell viability was determined spectrophotometrically as a change in $\mathrm{OD}_{600}$ in the assay medium. The $\beta$-galactosidase activity was calculated according to equations described previously by Gaido et al. (1997). Concentrations of a given chemical that caused significant cytotoxicity were excluded from the calculation, to ensure that the potency classification was not biased by cytotoxicity.

\subsection{Instrumental analysis}

The residues of water samples were redissolved in 0.4 $\mathrm{mL}$ of hexane that contained $50 \mu \mathrm{L}$ of the derivatization mixture BSTFA/TCMS $(99 / 1, V / V)$ and $1 \mathrm{mmol} / \mathrm{mL}$ of pyrene-d10. The derivatization was performed at $60^{\circ} \mathrm{C}$ for $2 \mathrm{hr}$. The derivatives were cooled at room temperature and stored at $4{ }^{\circ} \mathrm{C}$.

Instrumental analysis was performed within two days. The targets in the samples were detected by using an Agilent 6890 gas chromatograph equipped with an Agilent MSD 5975 mass spectrometer (USA). System control and data acquisition were achieved with ChemStation Software (USA). The capillary column of $30 \mathrm{~m} \times 0.25 \mathrm{~mm}$ i.d. 0.25 $\mu \mathrm{m}$ DB-5 was applied. Before analyzing samples, retention time was locked by changing column pressure, followed by the use of a constant pressure model in the whole analysis process. For part 1, the GC oven temperature programs were as follows: the initial temperature of $80^{\circ} \mathrm{C}$ was held for $1 \mathrm{~min}$, then increased to $200^{\circ} \mathrm{C}$ at a rate of $20^{\circ} \mathrm{C} / \mathrm{min}$, then to $300^{\circ} \mathrm{C}$ at a rate of $10^{\circ} \mathrm{C} / \mathrm{min}$, and then held for 10 min, with a total run time of $27 \mathrm{~min}$. For part 2, the GC oven temperature was programmed from 40 to $300^{\circ} \mathrm{C}$ via a ramp of $10^{\circ} \mathrm{C} / \mathrm{min}$ and maintained at $40^{\circ} \mathrm{C}$ for $1 \mathrm{~min}$ and then at $300^{\circ} \mathrm{C}$ for $15 \mathrm{~min}$. The MS was operated in selected ion monitoring (SIM) mode for quantitative analysis. The inlet and MS transfer line temperatures were maintained at $300^{\circ} \mathrm{C}\left(250^{\circ} \mathrm{C}\right.$ for part 2$)$, and the ion source temperature was $230^{\circ} \mathrm{C}\left(300^{\circ} \mathrm{C}\right.$ for part 2$)$. Sample injection $(1 \mu \mathrm{L})$ was in splitless mode. In order to ensure the accuracy of the analysis, all of the assays were repeated three times.

\subsection{Causality analysis}

The $\beta$-galactosidase activities for sample extracts were obtained and calibrated according to the dose-response curve of E2 standard solutions, derived simultaneously. The $\mathrm{EEQ}_{\text {bio }}$ (EEQ derived from bioassay) values were calculated according to the dose-response curve of E2. The $\mathrm{EEQ}_{\mathrm{cal}}$ (EEQ derived from chemical analysis) values were calculated from the concentrations of the analyzed target compounds using the following equation:

$$
\mathrm{EEQ}_{\mathrm{cal}}=\sum \mathrm{EEQ}_{i}=\sum\left(C_{i} \times \mathrm{RP}_{i}\right)
$$

where, $\mathrm{EEQ}_{i}$ represents the EEQ value of selected compound $i, C_{i}$ was the relative potency of selected compound $i$, and $\mathrm{RP}_{i}$ represented the relative potency of selected compound $i$, obtained from the ratio between $\mathrm{EC}_{50}$ of $\mathrm{E} 2$ and that of other target chemical. The RP values of E1, E2, EE2, E3, DES, EV, 4-t-OP, 4-NP and BPA were 0.053, $1,0.17,0.0049,0.021,0.14,0.0012,0.0007$ and 0.00003, respectively. The percentile contribution of the selected compounds $\left(\mathrm{EEQ}_{i}\right)$ in the $\mathrm{EEQ}_{\text {bio }}$ was then calculated. 


\subsection{Quality control}

All data generated from the analysis were subject to strict quality control procedures. To check for background contamination, peak identification and quantification, a solvent blank, a standard blank and a procedure blank were processed in sequence along with each set of samples to be analyzed. Surrogate standards were added to all the samples to monitor matrix effects; recoveries of surrogate standards E2-d3 and BPA-d16 were 94\% and $83 \%$ respectively. Relative recoveries of the nine estrogenic compounds ranged from $81 \%$ to $116 \%$ for the source water samples at the spiked concentration of $5 \mathrm{ng} / \mathrm{L}$. The calculations of the limit of detection (LOD) and limit of quantitation (LOQ) of the target compounds were based on the standard derivations (SD) of seven replicates of spiked water at the concentration of $5 \mathrm{ng} / \mathrm{L}$. LOD was defined as three times SD and LOQ is as nine times SD. The LOD and LOQ for source water were 0.10 to 0.65 $\mathrm{ng} / \mathrm{L}$ and 0.20 to $1.3 \mathrm{ng} / \mathrm{L}$, respectively. For bioassay, the $\beta$-galactosidase activities of the samples were examined and compared with those of the controls. Significant doseresponse relationships were obtained by testing samples at serial dilutions.

To avoid contamination during the sampling and sample preparation processes, sampling bottles and all glassware involved in the study were cleaned by soaking in $10 \%$ nitric acid overnight and chromic acid solution for 30 min, washing three times with double-distilled water, and burning in a muffle furnace at $450^{\circ} \mathrm{C}$ for at least $4 \mathrm{hr}$. All laboratory materials were made of either glass or polytetrafluoroethene (PTFE) to avoid sample contamination.

\section{Results and discussion}

\subsection{Estrogenic activities in source waters}

All extracts of source waters were found to induce significant estrogenic activities (Fig. 1). The EEQ bio values ranged from 0.16 to $2.4 \mathrm{ng} / \mathrm{L}$, and six out of 23 sites were found to have values of above $1.0 \mathrm{ng} / \mathrm{L}$. Higher EEQ $\mathrm{bio}$ values have been found at sampling sites 12, 14 and 15, whose $\mathrm{EEQ}_{\text {bio }}$ values were higher than $2.0 \mathrm{ng} / \mathrm{L}$. Most source waters with high EEQ values were located in the Yangtze River Delta, which is the most developed region in China, receiving sewage discharged from up-stream cities.

Table 2 summarizes the published results on EEQ bio derived from various bioassay methods for different sampling sites around the world. The EEQbio value of Taihu Lake, also located in Yangtze River Delta, was extraordinarily higher than values from other sources. In contrast, $\mathrm{EEQ}_{\text {bio }}$ values were often relatively low in samples from European countries, which are well known for their successful environmental protection policies and advanced technologies. Nevertheless, conclusions from bioassay results can only be drawn in a very general way. Concentrations vary considerably in different types of waters and at different sites. Furthermore, differences in sampling methods and analysis techniques, notably for bioassay, can often obstruct detailed comparisons (Vethaak et al., 2005).

\subsection{Concentrations of estrogenic compounds in source waters}

The presence of the selected compounds in source waters varied spatially, except for DES and EV (Table 3). Among 16 samples, E1, 4-t-OP, 4-NP and BPA prevailed in all

Table 2 Comparisons of estrogenic activities derived from bioassays carried in different countries

\begin{tabular}{llll}
\hline Location & EEQ (ng/L) & Bioassay & Reference \\
\hline Netherlands & $<0.17$ & ER-CALUX & Vethaak et al., 2005 \\
France & $0.30-4.52$ & MELN & Cargouët et al., 2004 \\
Switzerland & $0.3-7.0$ & Yeast & Vermeirssen et al., 2005 \\
South Africa & $0.63-2.48$ & Yeast & Aneck-Hahn et al., 2009 \\
Japan & $0.7-4.01$ & MVLN & Hashimoto et al., 2005 \\
South Korea & $0.38-6.27$ & E-Screen & Ra et al., 2011 \\
China & $2.2-8.3$ & HGELN & Shen et al., 2001 \\
China & $0.08-2.4$ & Yeast & This study \\
\hline
\end{tabular}

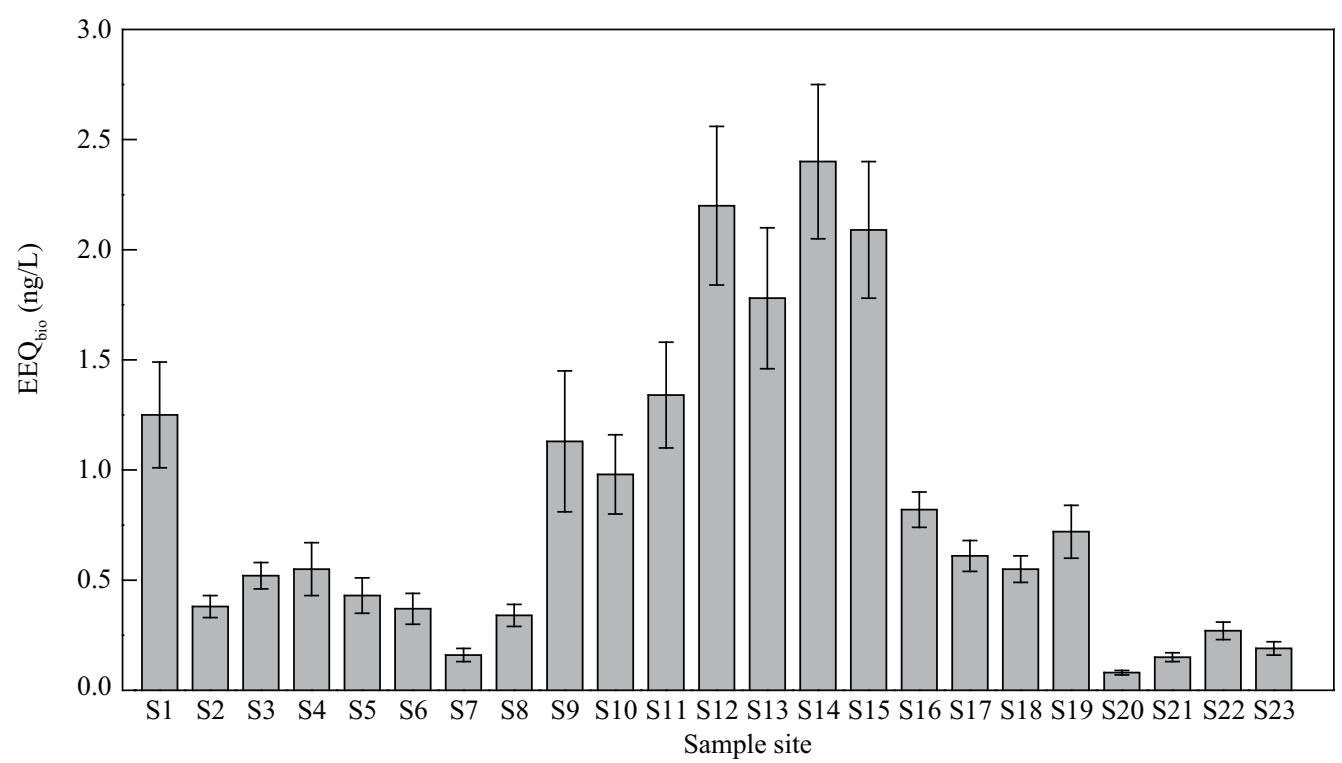

Fig. $1 \mathrm{EEQ}_{\text {bio }}$ values of source waters derived from yeast assay. Error bars represent the standard deviation of replicate samples $(n=3)$. EEQ bio: bioassay derived E2 (estradiol) equivalent. 
Table 3 Concentrations of selected compounds in source waters (unit: ng/L)

\begin{tabular}{|c|c|c|c|c|c|c|c|c|c|}
\hline Site & E1 & E2 & EE2 & E3 & DES & EV & 4-t-OP & 4-NP & BPA \\
\hline S3 & $1.15 \pm 0.12$ & $0.31 \pm 0.08$ & $1.01 \pm 0.09$ & $\mathrm{nc}$ & nd & nd & $4.01 \pm 0.75$ & $30.05 \pm 3.97$ & $17.86 \pm 3.24$ \\
\hline $\mathrm{S} 4$ & $0.97 \pm 0.11$ & $0.28 \pm 0.03$ & $0.64 \pm 0.07$ & $\mathrm{nc}$ & nd & nd & $3.64 \pm 0.55$ & $54.27 \pm 7.34$ & $12.44 \pm 1.56$ \\
\hline S5 & $0.45 \pm 0.07$ & $\mathrm{nc}$ & $1.55 \pm 0.23$ & nd & nd & nd & $5.21 \pm 0.78$ & $109.22 \pm 12.37$ & $7.61 \pm 0.95$ \\
\hline S6 & $1.53 \pm 0.09$ & $0.26 \pm 0.01$ & $1.34 \pm 0.17$ & nd & nd & nd & $15.69 \pm 2.34$ & $168.25 \pm 5.48$ & $152.98 \pm 10.57$ \\
\hline S7 & $0.96 \pm 0.08$ & $0.34 \pm 0.05$ & $0.28 \pm 0.03$ & $\mathrm{nc}$ & nd & nd & $12.42 \pm 1.56$ & $100.21 \pm 7.97$ & $135.14 \pm 9.34$ \\
\hline S8 & $0.87 \pm 0.09$ & $0.31 \pm 0.02$ & $\mathrm{nc}$ & $\mathrm{nc}$ & nd & nd & $13.78 \pm 1.47$ & $123.58 \pm 10.29$ & $124.73 \pm 8.41$ \\
\hline S9 & $1.08 \pm 0.08$ & $0.55 \pm 0.04$ & $\mathrm{nc}$ & $4.37 \pm 0.38$ & nd & nd & $37.62 \pm 5.14$ & $280.19 \pm 17.67$ & $80.32 \pm 5.32$ \\
\hline S10 & $1.93 \pm 0.23$ & $0.71 \pm 0.13$ & nd & $3.94 \pm 0.31$ & nd & nd & $96.44 \pm 7.63$ & $288.75 \pm 21.48$ & $65.04 \pm 5.14$ \\
\hline S11 & $2.37 \pm 0.17$ & $0.58 \pm 0.04$ & nd & $4.22 \pm 0.22$ & nd & nd & $69.29 \pm 5.49$ & $212.39 \pm 14.63$ & $90.65 \pm 8.26$ \\
\hline $\mathrm{S} 12$ & $2.34 \pm 0.14$ & $1.07 \pm 0.03$ & $1.68 \pm 0.16$ & $2.14 \pm 0.04$ & $\mathrm{nc}$ & $\mathrm{nc}$ & $53.68 \pm 4.18$ & $232.73 \pm 14.65$ & $147.69 \pm 12.59$ \\
\hline S13 & $2.89 \pm 0.18$ & $1.78 \pm 0.10$ & $2.67 \pm 0.09$ & $2.73 \pm 0.17$ & $2.07 \pm 0.16$ & $1.96 \pm 0.23$ & $65.26 \pm 3.89$ & $230.84 \pm 16.52$ & $276.97 \pm 20.48$ \\
\hline S14 & $2.98 \pm 0.24$ & $1.51 \pm 0.07$ & $2.59 \pm 0.18$ & $2.97 \pm 0.21$ & $2.52 \pm 0.18$ & $1.57 \pm 0.07$ & $89.52 \pm 7.63$ & $259.63 \pm 14.21$ & $710.65 \pm 39.52$ \\
\hline S15 & $2.13 \pm 0.12$ & $0.65 \pm 0.06$ & $2.53 \pm 0.31$ & $2.68 \pm 0.17$ & $2.31 \pm 0.30$ & $1.34 \pm 0.07$ & $73.57 \pm 5.23$ & $224.13 \pm 18.57$ & $268.32 \pm 22.36$ \\
\hline S20 & $0.52 \pm 0.04$ & $\mathrm{nc}$ & $\mathrm{nc}$ & $\mathrm{nc}$ & nd & nd & $4.52 \pm 0.38$ & $58.33 \pm 4.23$ & $32.02 \pm 2.65$ \\
\hline $\mathrm{S} 21$ & $0.86 \pm 0.11$ & $\mathrm{nc}$ & $\mathrm{nc}$ & $\mathrm{nc}$ & nd & nd & $3.34 \pm 0.25$ & $85.16 \pm 7.45$ & $27.08 \pm 1.29$ \\
\hline $\mathrm{S} 22$ & $0.97 \pm 0.14$ & $0.11 \pm 0.01$ & $\mathrm{nc}$ & $\mathrm{nc}$ & nd & nd & $3.08 \pm 0.26$ & $72.65 \pm 4.96$ & $25.24 \pm 1.72$ \\
\hline
\end{tabular}

E1: estrone, E2: 17ß-estradiol, EE2: 17 $\alpha$-ethinylestradiol, E3: estriol, DES: diethylstilbestrol, EV: estradiol valerate, 4-t-OP: 4-t-octylphenol, 4-NP: 4-nonylphenols, BPA: bisphenol A.

Data are expressed as mean \pm standard deviation $(n=3)$; nc: below limit of quantification, nd: below detection limit.

samples, with concentrations ranging of $0.16-2.98 ; 3.08-$ 89.52; 30.09-280.19; and 7.61-710.65, respectively. E2, EE2 and E3 were partially detected but some were below LOQ, with concentrations ranging from nc $(<\mathrm{LOQ}$, cannot be calculated) to $1.07 \mathrm{ng} / \mathrm{L}$, nd ( $<\mathrm{LOD}$, cannot be detected) to $2.67 \mathrm{ng} / \mathrm{L}$, and nd to $4.37 \mathrm{ng} / \mathrm{L}$, respectively. In contrast, DES and EV could only be quantified in three samples, with concentrations ranging from 2.07 to $2.52 \mathrm{ng} / \mathrm{L}$ and 1.34 to $1.96 \mathrm{ng} / \mathrm{L}$, respectively. In general, concentrations of 4-t-OP, 4-NP and BPA were much higher than other six compounds. These sites were all located in metropolitan areas, especially the Yangtze River Delta, showing similar distribution patterns of bioassay results.

In Table 4, the concentration ranges of nine selected estrogenic compounds in source waters were compared to those of previous studies in both source and surface waters. In the work of Lu et al. (2010), concentrations of E1, E2, E3, 4-t-OP, 4-NP and BPA were found in the Yangtze River (Nanjing section) of up to 3.80, 0.97, $5.79,95.77,536.55$ and $60.69 \mathrm{ng} / \mathrm{L}$, respectively. These are similar to those determined in the present study. The concentrations of E1, E2, EE2, NP and BPA in source waters in the USA were up to $0.90,17,1.4,130$ and 14 ng/L, respectively (Benotti et al., 2009). Very few studies have been carried out on DES and EV, so they were not included in the comparison. Similar to the previous studies, the presently observed concentrations of 4-t-OP, 4-NP and BPA in source waters were remarkably higher than other compounds in the present study.

\subsection{Risk assessment and causality analysis}

The presence of estrogenic activity in source waters might affect aquatic organisms in such waters by disrupting their normal hormonal functions and jeopardizing the source water quality. It was previously proposed that, for E2, a tentative long term predicted no-effect concentration (PNEC) for freshwater life was $1 \mathrm{ng} / \mathrm{L}$ (Young et al., 2002). According to this concept, the reproductive system of organism live in the aquatic environment of which EEQ values higher than $1 \mathrm{ng} / \mathrm{L}$ might be disrupted.
In the present study, the calculation of $\mathrm{EEQ}_{\mathrm{cal}}$ values was based on the concept of concentration addition from chemical analysis, representing the sum of estrogenic activities of nine selected compounds in the present study. A significant correlation between $\mathrm{EEQ}_{\mathrm{cal}}$ and $\mathrm{EEQ}_{\text {bio }}$ was observed (Fig. 2). For all samples, the $\mathrm{EEQ}_{\mathrm{cal}}$ values were not equal to, and were mostly lower than, the corresponding

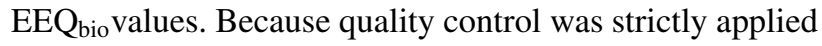
in the present study and selected compounds acted on the same target of ER, the disagreement between EEQ bio and $E Q_{c a l}$ could be due to the presence of unknown estrogen agonistic and antagonistic compounds in the water samples (Tanaka et al., 2001; Witters et al., 2001). This result confirmed the general robustness of both biological and chemical analysis tools. Moreover, these data indicated that the nine selected estrogen compounds represented the major contributors to total estrogenic activity.

To investigate the individual contribution of the nine selected compounds to total estrogenic activity, their EEQ values were compared with corresponding $\mathrm{EEQ}_{\mathrm{bio}}$ values. The contribution rate of E1, E2, EE2, E3, DES, EV, 4-t-

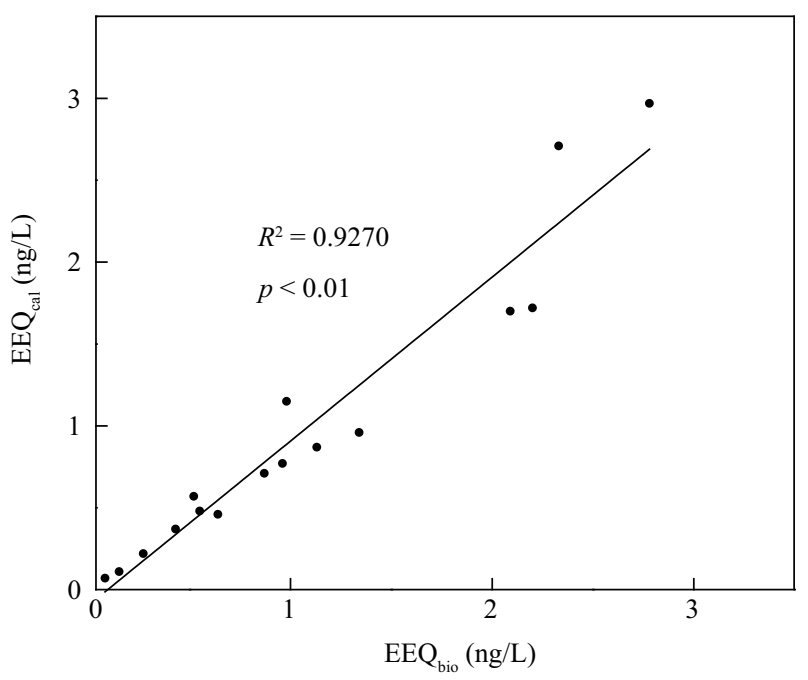

Fig. 2 Plots of the EEQ bio values versus $E_{E Q}$ cal values. $E_{E Q}$ : chemical analysis derived E2 (estradiol) equivalent. 
Table 4 Comparison of estrogenic compounds concentrations in water with other studies (unit: ng/L)

\begin{tabular}{lllllllll}
\hline Location & E1 & E2 & EE2 & E3 & 4-t-OP & 4-NP & BPA \\
\hline Germany & $0.1-4.1$ & $0.15-3.6$ & $0.1-5.1$ & - & $0.8-54$ & $6.7-134$ & $0.5-14$ & Keference \\
Greece & nd & nd & nd & nd & $5.0-78$ & $152-338$ & $15-138$ & Arditsoglou and Voutsa, 2010 \\
Portugal & nd & nd & nd & - & nd & - & nd-589.5 & Ribeiro et al., 2009 \\
USA & nd-0.9 & nd-17 & nd-1.4 & - & - & nd-130 & nd-14 & Benotti et al., 2008 \\
Austria & nd-4.6 & nd-1.2 & nd-0.33 & nd-1.9 & nd-41 & nd-890 & nd-600 & Hohenblum et al., 2004 \\
S. Korea & nd-5.0 & nd & nd & nd & - & - & Kim et al., 2007 \\
China & nd-3.80 & nd-0.97 & - & nd-5.79 & $89.07-95.77$ & $337.37-536.55$ & $34.55-60.69$ & Lu et al., 2010 \\
China & nd-75.0 & nd-7.5 & - & - & $1.0-2470$ & $28.1-8890$ & $2.2-1030$ & Zhao et al., 2009 \\
China & $0.45-3.0$ & nd-1.8 & nd-2.7 & nd-4.4 & $3.1-96.4$ & $30.1-288.8$ & $7.6-710.7$ & This study \\
\hline
\end{tabular}

-: not available; nd: not detected.

OP, 4-NP and BPA was in the range of 5.07\%-34.45\%, $0-72.45 \%, 0-61.28 \%, 0-1.97 \%$, 0-2.97\%, $0-12.35 \%$, $0.79 \%-11.81 \%, 4.05 \%-51.04 \%$ and $0.10 \%-2.53 \%$, respectively. It could be speculated that E2, EE2 and 4-NP played a major role in the estrogenic activity in source waters, especially E2 which was dominant in 12 out of 23 samples. The three compounds mentioned above together accounted for $39.74 \%$ to $96.68 \%$ (mean value $69.36 \%$ ) of $\mathrm{EEQ}_{\text {bio, }}$, while other compounds showed a minor contribution (Fig. 3, Table S1). None of these three compounds are listed in the Chinese drinking water quality standards document (MOH, 2006). It is important that these three compounds are included in future environmental regulations.

E2 belongs to a chemical family known as natural estrogens, and EE2 is an orally bioactive estrogen used in almost all modern oral contraceptive formulations. China is the country with the highest consumption of contraceptive pills, which explains the high concentrations of E2 and EE2 in Chinese water bodies (Stanback, 1997). When these compounds enter the environment, they can cause male reproductive dysfunction in wildlife (Wang et al., 2008). Traditional water treatment processes, such as chlorination, coagulation and sedimentation do not adequately remove EDCs. Water purification techniques such as ultraviolet, ozonation and activated charcoal have a great removal efficiency, but the high costs of these techniques represent a major constraint on the widespread use of these techniques (Johnson and Sumpter, 2001; Chen et al., 2007; Guedes Maniero et al., 2008).

4-NP is a mixture group of nonylphenol (NPs), which is persistent in the environment and mainly arise from the degradation of the nonylphenol ethoxylates (NPEOs) in the environment. NPEOs are a subset of the alkylphenols ethoxylates (APEOs) that are used as surfactants in detergents, encompassing more than $80 \%$ of the world market of APEOs, of which the total annual world-wide production was about 700,000 tons in 2005 (Jonkers et al., 2005). NPs and NPEOs have been classified in the European Union as a hazard to human and environmental safety (European Union, 2003). In the USA, these compounds have been removed from laundry detergents (McCoy, 2007). Nevertheless, these compounds have not been effectively restricted in China. The NPEOs are found in various Chinese rivers at concentrations of up to 97.6 $\mu \mathrm{g} / \mathrm{L}$ (Shao et al., 2005; Shen et al., 2005; Yu et al., 2009). In contrast to $\mathrm{E} 2$ and EE2, the estrogenic activity of 4-NP is very weak because 4-NP is a weak structural mimic of E2, but the levels of 4-NP can be extraordinary high to compensate (Soares et al., 2008). The NP removal efficiency in

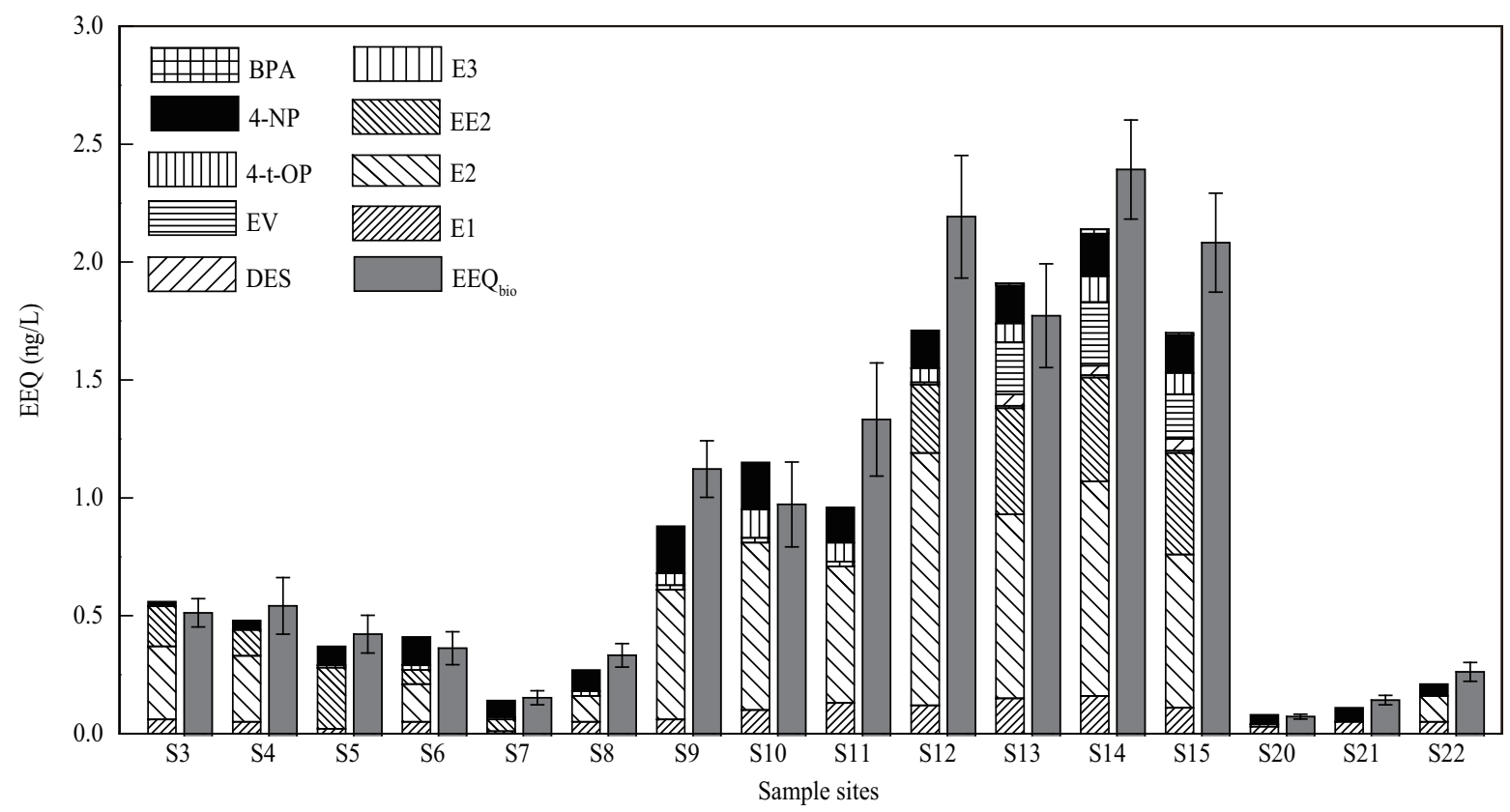

Fig. 3 Calculated EEQ values of selected compounds versus EEQbio values. 
drinking water treatment systems, was found to be highly variable depending on the type of unit treatment process employed, and facilities with high elimination rates adopt ozonation in their treatment processes (Berryman, 2004).

Although it is well known that EDCs can affect the endocrine systems of aquatic organisms, even at low concentrations, it is hard to explain possible health risks to humans based on the results from laboratory experiments, particularly with regard to chronic effects, such as endocrine disrupting (Rogan and Ragan, 2003). However, humans are exposed to mixtures of EDCs and it is necessary to consider the impact of synergistic effects of these compounds (Kortenkamp, 2007). The potential risk of mixtures of chemicals at low-effect levels has become known as the "something from nothing" phenomenon (Silva et al., 2002). Risk assessments that overlook the possibility of synergistic effects of EDCs are likely to significantly undervalue risks (Kortenkamp et al., 2007). For example, Payne et al. (2001) found that the mixture of four organchlorines, each of them present at a low and individually-ineffective concentration, enhanced human breast cancer cell proliferation. On the another hand, some EDCs are persistent in the environment and can be accumulated in human body (Bianco et al., 2011). Hence, the impacts to humans of the EDCs in Chinese source waters should not be ignored, even though current data on the relationship between exposure to environmental EDCs and human health remains limited (Diamanti-Kandarakis et al., 2010). To take precaution, certain measures can be taken to decrease levels of EDCs in source waters, such as restricting pollution discharge upstream of source waters, and introducing proper treatment processes.

\section{Conclusions}

Estrogenic activity has been observed in all 23 source waters of China. Samples from the Yangtze Delta indicated higher estrogenic potential than in other source water samples. The nine selected compounds, found in various source waters, represent most of the whole estrogenic activity. Furthermore, E2, EE2 and 4-NP were found to be the main contributors to the estrogenic activities in most source waters out of nine selected compounds. Results of the present work could be useful to water treatment technology and environmental risk assessment.

\section{Acknowledgments}

This work was supported by the Chinese Academy of Sciences (No. KZCX1-YW-06-02), the National Basic Research Program of China (No. 2007CB407304), and the Ministry of Environmental Protection of the People's Republic of China (No. 200909040).

\section{Supporting materials}

Supplementary data associated with this article can be found in the online version.

\section{References}

Aneck-Hahn N H, Bornman M S, de Jager C, 2009. Oestrogenic activity in drinking waters from a rural area in the Waterberg District, Limpopo Province, South Africa. Water South Africa, 35(3): 245-251.

Arditsoglou A, Voutsa D, 2010. Partitioning of endocrine disrupting compounds in inland waters and wastewaters discharged into the coastal area of Thessaloniki, Northern Greece. Environmental Science and Pollution Research, 17(3): 529538.

Benotti M J, Trenholm R A, Vanderford B J, Holady J C, Stanford B D, Snyder S A, 2009. Pharmaceuticals and endocrine disrupting compounds in U.S. drinking water. Environmental Science and Technology, 43(3): 597-603.

Berryman D, Houde F, DeBlois C, O'Shea M, 2004. Nonylphenolic compounds in drinking and surface waters downstream of treated textile and pulp and paper effluents: a survey and preliminary assessment of their potential effects on public health and aquatic life. Chemosphere, 56(3): 247-255.

Bianco M, Mita L, Portaccio M, Diano N, Sica V, De Luca B et al., 2011. Differential accumulation levels in the brain of rats exposed to the endocrine disruptor 4-tert-octylphenol (OP). Environmental Toxicology and Pharmacology, 31(1): 198-204.

Campbell C G, Borglin S E, Green F B, Grayson A, Wozei E, Stringfellow W T, 2006. Biologically directed environmental monitoring, fate, and transport of estrogenic endocrine disrupting compounds in water: A review. Chemosphere, 65(8): 1265-1280.

Cargouët M, Perdiz D, Mouatassim-Souali A, Tamisier-Karolak S, Levi Y, 2004. Assessment of river contamination by estrogenic compounds in Paris area (France). Science of the Total Environment, 324(1-3): 55-66.

Chen C Y, Wen T Y, Wang G S, Cheng H W, Lin Y H, Lien G W, 2007. Determining estrogenic steroids in Taipei waters and removal in drinking water treatment using high-flow solidphase extraction and liquid chromatography/tandem mass spectrometry. Science of the Total Environment, 378(3): 352-365.

Damstra T, Barlow S, Bergman A, Kavlock R, Van Der Kraak G, 2002. Global assessment of the state-of-the-science of endocrine disruptors. International Programme on Chemical Safety, World Health Organization. Geneva, Switzerland.

Desbrow C, Routledge E J, Brighty G C, Sumpter J P, Waldock M, 1998. Identification of estrogenic chemicals in STW effluent. 1. Chemical fractionation and in vitro biological screening. Environmental Science and Technology, 32(11): 1549-1558.

Diamanti-Kandarakis E, Palioura E, Kandarakis S A, Koutsilieris M, 2010. The impact of endocrine disruptors on endocrine targets. Hormone and Metaolic Research, 42(8): 543-552.

European Union, 2003. Directive 2003/53/EC of the European Parliament and of the Council 18 June 2003. Luxembourg.

Gaido K W, Leonard L S, Lovell S, Gould J C, Babai D, Portier C J et al., 1997. Evaluation of chemicals with endocrine modulating activity in a yeast-based steroid hormone receptor gene transcription assay. Toxicology and Applied Pharmacology, 143(1): 205-212.

Guedes Maniero M, Maia Bila D, Dezotti M, 2008. Degradation and estrogenic activity removal of $17 \beta$-estradiol and $17 \alpha-$ ethinylestradiol by ozonation and $\mathrm{O}_{3} / \mathrm{H}_{2} \mathrm{O}_{2}$. Science of the Total Environment, 407(1): 105-115.

Hashimoto S, Horiuchi A, Yoshimoto T, Nakao M, Omura H, 
Kato Y et al., 2005. Horizontal and vertical distribution of estrogenic activities in sediments and waters from Tokyo Bay, Japan. Archives of Environmental Contamination and Toxicology, 48(2): 209-216.

Hohenblum P, Gans O, Moche W, Scharf S, Lorbeer G, 2004. Monitoring of selected estrogenic hormones and industrial chemicals in groundwaters and surface waters in Austria. Science of the Total Environment, 333(1-3): 185-193.

Johnson A C, Sumpter J P, 2001. Removal of endocrinedisrupting chemicals in activated sludge treatment works. Environmental Science and Technology, 35(24): 46974703.

Jonkers N, Laane R W P M, de Voogt P, 2005. Sources and fate of nonylphenol ethoxylates and their metabolites in the Dutch coastal zone of the North Sea. Marine Chemistry, 96(1-2): $115-135$.

Jonkers N, Sousa A, Galante-Oliveira S, Barroso C M, Kohler H P E, Giger W, 2010. Occurrence and sources of selected phenolic endocrine disruptors in Ria de Aveiro, Portugal. Environmental Science and Pollution Research, 17(4): 834843.

Kasprzyk-Hordern B, Dinsdale R M, Guwy A J, 2008. The occurrence of pharmaceuticals, personal care products, endocrine disruptors and illicit drugs in surface water in South Wales, UK. Water Research, 42(13): 3498-3518.

Kim S D, Cho J, Kim I S, Vanderford B J, Snyder S A, 2007. Occurrence and removal of pharmaceuticals and endocrine disruptors in South Korean surface, drinking, and waste waters. Water Research, 41(5): 1013-1021.

Kortenkamp A, Faust M, Scholze M, Backhaus T, 2007. Low-level exposure to multiple chemicals: Reason for human health concerns? Environmental Health Perspectives, 115(S-1): 106-114.

Kortenkamp A, 2007. Ten years of mixing cocktails: A review of combination effects of endocrine-disrupting chemicals. Environmental Health Perspectives, 115(S-1): 98-105.

Kuch H M, Ballschmiter K, 2001. Determination of endocrinedisrupting phenolic compounds and estrogens in surface and drinking water by HRGC-(NCI)-MS in the picogram per liter range. Environmental Science and Technology, 35(15): 3201-3206.

Li J, Ma M, Wang Z J, 2010. In vitro profiling of endocrine disrupting effects of phenols. Toxicology in Vitro, 24(1): 201-207.

Augulyte L, Bergqvist P A, 2007. Estimation of water sampling rates and concentrations of PAHs in a municipal sewage treatment plant using SPMDs with performance reference compounds. Environmental Science and Technology, 41(14): 5044-5049.

Lu G H, Song W T, Wang C, Yan Z H, 2010. Assessment of in vivo estrogenic response and the identification of environmental estrogens in the Yangtze River (Nanjing section). Chemosphere, 80(9): 982-990.

Luo J P, Ma M, Wang Z J, Liu W L, Li T S, 2006. Assessment on the ecological risks of drink water in a city in North China by way of bioassay battery. Water and Wastewater Engineering, 32(8): 17-21.

Magi E, Scapolla C, Di Carro M, Liscio C, 2010. Determination of endocrine-disrupting compounds in drinking waters by fast liquid chromatography-tandem mass spectrometry. Journal of Mass Spectrometry, 45(9): 1003-1011.

Matthiessen P, Arnold D, Johnson A C, Pepper T J, Pottinger T G, Pulman K G T, 2006. Contamination of headwater streams in the United Kingdom by oestrogenic hormones from livestock farms. Science of the Total Environment, 367(2-3): 616-630.

McCoy M, 2007. Going green. Chemical and Engineering News, 85(5): 13-23.

MOH (Ministry of Health of the People's Republic of China), 2006. Standards for Drinking Water Quality. Beijing, China.

Payne J, Scholze M, Kortenkamp A, 2001. Mixtures of four organochlorines enhance human breast cancer cell proliferation. Environmental Health and Perspective, 109(4): 391-397.

Ra J S, Lee S H, Lee J, Kim H Y, Lim B J, Kim S H et al., 2011. Occurrence of estrogenic chemicals in South Korean surface waters and municipal wastewaters. Journal of Environmental Monitoring, 13(1): 101-109.

Rao K F, Ma M, Wang Z J, Liu L J, 2004. Variation of estrogenic effects during Water treatment processes in a drinking water work in South China. Chinese Journal of Environmental Science, 25(6): 123-126.

Reineke N, Bester K, Hühnerfuss H, Jastorff B, Weigel S, 2002. Bioassay-directed chemical analysis of River Elbe surface water including large volume extractions and high performance fractionation. Chemosphere, 47(7): 717-723.

Ribeiro C, Pardal M Â, Martinho F, Margalho R, Tiritan M E, Rocha $\mathrm{E}$ et al., 2009. Distribution of endocrine disruptors in the Mondego River estuary, Portugal. Environmental Monitoring and Assessment, 149(1-4): 183-193.

Rogan W J, Ragan N B, 2003. Evidence of effects of environmental chemicals on the endocrine system in children. Pediatrics, 112(S1): 247-252.

Shao B, Hu J Y, Yang M, An W, Tao S, 2005. Nonylphenol and nonylphenol ethoxylates in river water, drinking water, and fish tissues in the area of Chongqing, China. Archives of Environmental Contamination and Toxicology, 48(4): 467473.

Shen G, Zhang Z, Yu G, Li X, Hu H, Li F, 2005. Dissolved neutral nonylphenol ethoxylates metabolites in the Haihe River and Bohai Bay, People's Republic of China. Bulletin of Environmental Contamination and Toxicology, 75(4): 827834.

Shen J H, Gutendorf B, Vahl H H, Shen L, Westendorf J, 2001. Toxicological profile of pollutants in surface water from an area in Taihu Lake, Yangtze Delta. Toxicology, 166(1-2): $71-78$

Silva E, Rajapakse N, Kortenkamp A, 2002. Something from "nothing" - eight weak estrogenic chemicals combined at concentrations below NOECs produce significant mixture effects. Environmental Science and Technology, 36(8): $1751-1756$.

Soares A, Guieysse B, Jefferson B, Cartmell E, Lester J N, 2008. Nonylphenol in the environment: A critical review on occurrence, fate, toxicity and treatment in wastewaters. Environment International, 34(7): 1033-1049.

Stanback J, 1997. Perspectives on local manufacture of contraceptives in developing countries. Family Health International, Arlington, VA, USA.

Sumpter J P, 1997. Environmental control of fish reproduction: a different perspective. Fish Physiology and Biochemistry, 17(1-6): 25-31.

Tanaka H, Yakou Y, Takahashi A, Higashitani T, Komori K, 2001. Comparison between estrogenicities estimated from DNA recombinant yeast assay and from chemical analyses of endocrine disruptors during sewage treatment. Water Science and Technology, 43(2): 125-132.

Tashiro Y, Takemura A, Fujii H, Takahira K, Nakanishi Y, 2003. 
Livestock wastes as a source of estrogens and their effects on wildlife of Manko tidal flat, Okinawa. Marine Pollution Bulletin, 47(1-6): 143-147.

Vermeirssen E L M, Burki R, Joris C, Peter A, Segner H, Suter M J E et al., 2005. Characterization of the estrogenicity of swiss midland rivers using a recombinant yeast bioassay and plasma vitellogenin concentrations in feral male brown trout. Environmental Toxicology and Chemistry, 24(9): 2226-2233.

Vethaak A D, Lahr J, Schrap S M, Belfroid A C, Rijs G B J, Gerritsen A et al., 2005. An integrated assessment of estrogenic contamination and biological effects in the aquatic environment of The Netherlands. Chemosphere, 59(4): 511-524.

Wang F Y, Sun X, He S H, Jia L Z, Zhan W, Liang Z H, 2005. Determination of environmental estrogens in surface water and tap water. Journal of Environment and Health, 22(4): 284-286.

Wang S, Huang W, Fang G Z, Zhang Y, Qiao H, 2008. Analysis of steroidal estrogen residues in food and environmental samples. International Journal of Environmental Analytical
Chemistry, 88(1): 1-25.

Witters H E, Vangenechten C, Berckmans P, 2001. Detection of estrogenic activity in flemish surface waters using an in vitro recombinant assay with yeast cells. Water Science and Technology, 43(2): 117-123.

Yamazaki F, 1983. Sex control and manipulation in fish. Aquaculture, 33(1-4): 329-354.

Young W F, Whitehouse P, Johnson I, Sorokin N, 2002. Proposed predicted-no-effect-concentrations (PNECs) for natural and synthetic steroid oestrogens in surface waters. Environment Agency R\&D Technical Report P2-T04/1. England and Wales Environment Agency Bristol; 172.

Yu Y, Zhai H Y, Hou S G, Sun H W, 2009. Nonylphenol ethoxylates and their metabolites in sewage treatment plants and rivers of Tianjin, China. Chemosphere, 77(1): 1-7.

Zhao J L, Ying G G, Wang L, Yang J F, Yang X B, Yang L H et al., 2009. Determination of phenolic endocrine disrupting chemicals and acidic pharmaceuticals in surface water of the Pearl Rivers in South China by gas chromatographynegative chemical ionization-mass spectrometry. Science of the Total Environment, 407(2): 962-974. 
Assessment of source water contamination by estrogenic disrupting compounds in China

\section{Supporting materials}

Table S1 EEQ values of estrogenic compounds and EEQcal values (Unit: ng/L)

\begin{tabular}{|c|c|c|c|c|c|c|c|c|c|c|}
\hline Site & E1 & E2 & EE2 & E3 & DES & $\mathrm{EV}$ & 4-t-OP & 4-NP & BPA & $\mathrm{EEQ}_{\mathrm{cal}}$ \\
\hline S3 & 0.06 & 0.31 & 0.17 & - & - & - & - & 0.02 & 0.00 & 0.57 \\
\hline $\mathrm{S} 4$ & 0.05 & 0.28 & 0.11 & - & - & - & - & 0.04 & 0.00 & 0.48 \\
\hline S5 & 0.02 & - & 0.26 & - & - & - & 0.01 & 0.08 & 0.00 & 0.37 \\
\hline S6 & 0.05 & 0.16 & 0.06 & - & - & - & 0.02 & 0.12 & 0.00 & 0.41 \\
\hline S7 & 0.01 & - & 0.05 & - & - & - & 0.01 & 0.07 & 0.00 & 0.15 \\
\hline S8 & 0.05 & 0.11 & - & - & - & - & 0.02 & 0.09 & 0.00 & 0.26 \\
\hline S9 & 0.06 & 0.55 & - & 0.02 & - & - & 0.05 & 0.20 & 0.00 & 0.87 \\
\hline $\mathrm{S} 10$ & 0.1 & 0.71 & - & 0.02 & - & - & 0.12 & 0.20 & 0.00 & 1.15 \\
\hline S11 & 0.13 & 0.58 & - & 0.02 & - & - & 0.08 & 0.15 & 0.00 & 0.96 \\
\hline $\mathrm{S} 12$ & 0.12 & 1.07 & 0.29 & 0.01 & - & - & 0.06 & 0.16 & 0.00 & 1.72 \\
\hline S13 & 0.15 & 0.78 & 0.45 & 0.01 & 0.05 & 0.22 & 0.08 & 0.16 & 0.01 & 1.92 \\
\hline S14 & 0.16 & 0.91 & 0.44 & 0.01 & 0.04 & 0.27 & 0.11 & 0.18 & 0.02 & 2.15 \\
\hline S15 & 0.11 & 0.65 & 0.43 & 0.01 & 0.05 & 0.19 & 0.09 & 0.16 & 0.01 & 1.70 \\
\hline S20 & 0.03 & - & - & - & - & - & 0.01 & 0.04 & 0.00 & 0.07 \\
\hline S21 & 0.05 & - & - & - & - & - & - & 0.06 & 0.00 & 0.11 \\
\hline $\mathrm{S} 22$ & 0.05 & 0.11 & - & - & - & - & - & 0.05 & 0.00 & 0.22 \\
\hline
\end{tabular}

E1: estrone, E2: 17 $\beta$-estradiol, EE2: 17 $\alpha$-ethinylestradiol, E3: estriol, DES: diethylstilbestrol, EV: estradiol valerate, 4-t-OP: 4-t-octylphenol, 4-NP: 4-nonylphenols, BPA: bisphenol A, EEQ cal: sum of EEQ of above nine compounds; “-”: not available. 